\title{
Anatomía de especies mexicanas de los géneros Phoradendron y Psittacanthus, endémicos del Nuevo Mundo
}

\section{Anatomy of Mexican species of the genera Phoradendron and Psittacanthus, endemic to the New World}

\author{
Maricela Gómez-Sánchez ${ }^{1}$, Liliana J. Sánchez-Fuentes ${ }^{1}$ y Luis A. Salazar-Olivo² \\ ${ }^{1}$ Facultad de Ciencias Naturales, Universidad Autónoma de Querétaro. Avenida de las Ciencias s/n, Juriquilla, 76230 Querétaro, Qurétaro, México. \\ ${ }^{2}$ Instituto Potosino de Investigación Científica y Tecnológica. Camino a la presa San José 2055 Col. Lomas $4^{a}$ sección, 78216 San Luis Potosí, San Luis \\ Potosí, México. \\ \gomezs@uaq.mx
}

Resumen. Phoradendron y Psittacanthus habitan exclusivamente en América y agrupan plantas hemiparásitas. El conocimiento de la anatomía de especies mexicanas es escaso y son varias en las que no ha sido tratada. Este trabajo describe la anatomía de 5 especies de los géneros que arriba se mencionan a partir de cortes con micrótomo, a mano libre, macerados y diafanizados. Se hicieron pruebas histoquímicas en material fresco. Entre las especies existen caracteres comunes. La arquitectura foliar se describe como venación actinódroma reticulada y venas laterales con las vénulas modificadas en traqueidas dilatadas. Anatómicamente, la hoja mostró estomas paracíticos y mesofilo isobilateral. Las drusas son abundantes en pecíolo y lámina de Phoradendron. El tallo presenta los vasos del xilema en hileras radiales, el parénquima cortical y la médula contienen drusas y braquiesclereidas. El polen es esférico o triangular y tricolporado. Psittacanthus se distingue porque debajo del ovario se desarrolla un tejido de células con paredes engrosadas y lignificadas y el fruto contiene una viscina conspicua. Los cristales prismáticos, la cutícula rugosa, la peridermis con tejido suberoso y los haces vasculares en el exocarpo, no se habían descrito anteriormente. Las astroesclereidas cristalíferas, el córtex heterogéneo, el epitelio cuticular y la cutícula estriada que citan otros autores, no se observaron. Las substancias pécticas y los compuestos fenólicos tienen mayor presencia en Psittacanthus.

Palabras clave: anatomía vegetal, plantas medicinales, muérdago, hemiparásitas, Loranthaceae, Viscaceae.

\begin{abstract}
Phoradendron and Psittacanthus only grow in America and they include hemiparasitic plants. The anatomy of Mexican species is partial and some of them had not anatomically been studied. The vegetative and reproductive anatomy of 5 species was described as seen in slides obtained through microtome, by free hand, and macerated and clarified tissues. Histochemistry tests on fresh material were made. The leaves have paracytic stomata, reticulate actinodromous venation, lateral veins with terminal portions modified to dilated tracheids and isobilateral or homogenous mesophyll. Druses are abundant in petiole and lamina of Phoradendron. The stem has xylem vessels in radial raws and druses and brachysclereids are common in the cortical parenchyma and the pith. Pollen is spherical or triangular and tricolporate. In Psittacanthus, under ovary a tissue of cells with lignified and thickness walls is present. The viscid tissue of the fruit of Psittacanthus is bigger. Prismatic crystals, striated cuticle, suberous peridermis and vascular bundles in the exocarp had not previously been described in these species. Astrosclereids with prismatic crystals, a heterogeneous cortex, a cuticular epithelium and a striated cuticle described for other authors were not found. Pectic substances and phenolic compounds are most abundant in Psittacanthus.
\end{abstract}

Key words: plant anatomy, medicinal plants, mistletoe, hemiparasitic, Loranthaceae, Viscaceae.

\section{Introducción}

Los géneros Phoradendron Nutt. y Psittacanthus Mart. agrupan especies comúnmente conocidas como muérdago o injerto y pertenecen a las familias Viscaceae y Loranthaceae respectivamente. Estas plantas son aéreas, hemiparásitas

Recibido: 29 octubre 2009; aceptado: 06 abril 2011 y crecen sobre distintas especies de gimnospermas y de angiospermas, incluidas otras especies de muérdago. Los frutos de estas parásitas tienen un tejido viscoso (viscina) que recubre las semillas, las cuales, al germinar producen una raíz modificada llamada haustorio que penetra en el cuerpo de la planta hospedera y llega hasta el xilema de donde extrae agua y sales minerales, causándole algunos trastornos que dan lugar a la formación de tumores leñosos. (Geils y Vázquez, 2002; Sosa y Tressens, 2002; Pöll, 2006). 
Phoradendron (Fig. 1A) incluye arbustos perennes, monoicos o dioicos, con hojas en pares y simples y decusadas de forma variable que van de falcadas a liguliformes o lanceoladas a estrechamente elípticas. Inflorescencia de 1 o varias espigas axilares, cada espiga con 1 o varios artículos fértiles y cada artículo con 2 o más hileras de flores. Flores unisexuales, sésiles, de color verde a amarillento; las estaminadas con 3 o más pétalos valvados, 3 o 4 anteras biloculares y pistilo rudimentario en el centro; las carpeladas con ovario unilocular, estilo recto originándose de un pequeño disco anular y estigma no diferenciado. El fruto es una baya blanquecina, ovoide a globosa, con 1 semilla rodeada por una capa víscida.

Psittacanthus (Fig. 1B) agrupa arbustos perennes, con hojas en pares y simples, estipuladas y comúnmente decusadas, de forma variable que va de falcada hasta ovada u obovada. Inflorescencia terminal o axilar en umbela o racimo indeterminado con varias triadas o diadas de flores hermafroditas. Flores de color rojo a anaranjado o escarlata brillante, estambres rojo-anaranjados; estilo tan largo como los pétalos, liso y recto; estigma más o menos capitado y finamente papilado. El fruto es una baya grande, azulada a negruzca, a veces con el calículo acrescente, con 1 semilla rodeada por abundante tejido víscido.

Estos 2 géneros son propiamente continentales y habitan en zonas templadas y tropicales del Nuevo Mundo. Su distribución en el continente americano es amplia, va desde el centro de Baja California y sur de Sonora, pasando por Mesoamérica hasta Bolivia y norte de Argentina, y es en México donde ocurre un traslapo importante de su presencia (Kuijt, 1986b, 1986c; Oliva, 1995; Geils et al., 2002; Geils y Vázquez, 2002; Sosa y Tressens, 2002; Vázquez y Geils, 2002; Kuijt, 2003, 2009).

Los muérdagos o injertos perjudican a su hospedero en menor o mayor grado, produciéndole en ocasiones la muerte (García, 1998). No obstante, estas plantas son importantes por su empleo en la medicina tradicional mexicana para tratar enfermedades como cáncer, hipertensión, afecciones cardiacas, afecciones en la piel y para controlar los niveles de glucemia en pacientes con diabetes mellitus (Roberts, 1989; Varela et al., 2004; Calzado-Flores et al., 2005; Alonso-Castro et al., 2011), entre otras. Aunque su conocimiento popular es extenso, pocos son los estudios que confirmen este uso tradicional de las especies. Sin embargo, investigaciones recientes (Johansson et al., 2003; Rodríguez-Cruz et al., 2003; Cervantes Badillo, 2006) sugieren que los muérdagos americanos son fuente importante de compuestos bioactivos y a los extractos de estas especies se les atribuyen algunas propiedades bioquímicas capaces de modificar respuestas biológicas tales como acciones inmunomodulatorias y antitumorales (Varela et al., 2004).
Algunas investigaciones basan su estudio en el muérdago europeo Viscum album (Varela et al., 2004), otros aportan datos parciales de 1 o 2 órganos vegetativos (Varela y Gurni, 1995; Ashworth, 1997; Ashworth y Dos Santos, 1997; Dettke y Milaneze-Gutierre, 2007), o bien, son estudios generales de otros géneros como Struthanthus (Venturelli, 1984), de la familia Loranthaceae (Metcalfe y Chalk, 1950; Sosa, 2003) o del orden Santalales (Wilson y Calvin, 2003). En este trabajo se describe y analiza la anatomía de órganos vegetativos y reproductivos de algunas especies mexicanas de Phoradendron y Psittacanthus y se comparan sus rasgos anatómicos.

\section{Materiales y métodos}

Las plantas se colectaron en el estado de Querétaro: Phoradendron brachystachyum (DC.) Eichl., Phoradendron carneum Urb. y Phoradendron forestierae Rob. et Greenm., en el municipio de Querétaro, parque ecológico La Joya-La Barreta, L. J. Sánchez 30, L. J. Sánchez 49, L. J. Sánchez 54; Psittacanthus calyculatus (DC.) G. Don, en los alrededores de la ciudad de Querétaro, L. J. Sánchez 116 y Psittacanthus palmeri (S. Watson) Barlow et Wiens, en el cañón Los Cajones, L. J. Sánchez 120. Los ejemplares de respaldo están en el herbario QMEX (Holmgren, 1990) de la Facultad de Ciencias Naturales, Universidad Autónoma de Querétaro.

Las muestras de hojas, pecíolos, tallos jóvenes y maduros, flores en antesis y frutos maduros se fijaron en una solución de formaldehído 10\%-acido acético 5\%-alcohol $50 \%$-agua $35 \%$ durante 24 horas y se almacenaron en alcohol al 70\%. Las flores, antes de su proceso, se dividieron longitudinalmente a la mitad y se describieron sus verticilos florales en vista longitudinal considerando los sistemas epidérmico, fundamental y vascular. Para obtener los cortes histológicos, las muestras se deshidrataron en una serie de alcohol etílico-alcohol terbutílico (Johansen, 1940), se incluyeron en parafina y se seccionaron con un micrótomo de rotación Leica a $12 \mu \mathrm{m}$ de espesor. Los cortes se tiñeron con safranina-verde rápido y se montaron con Permaunt. Los diafanizados se hicieron con alcohol 80\%-hidróxido de sodio $10 \%$ y se tiñeron con fucsina y verde rápido (Fuchs, 1963). Para la obtención del material disociado se empleó la solución de Jeffrey (Johansen, 1940), para las hojas se empleó $\mathrm{NaOH}$ al 5\% (Varela y Gurni, 2003). El polen se obtuvo directamente de la antera y se trató con la técnica de acetólisis adaptada de Erdtman (1966). Algunas pruebas histoquímicas simples se hicieron en cortes a mano libre de material fresco de hoja, tallo y fruto y se montaron con gelatina glicerinada para detectar algunas substancias. Para lípidos, se empleó sudán III; azul de toluidina y rojo de rutenio para substancias pécticas (mucílago), lugol para 


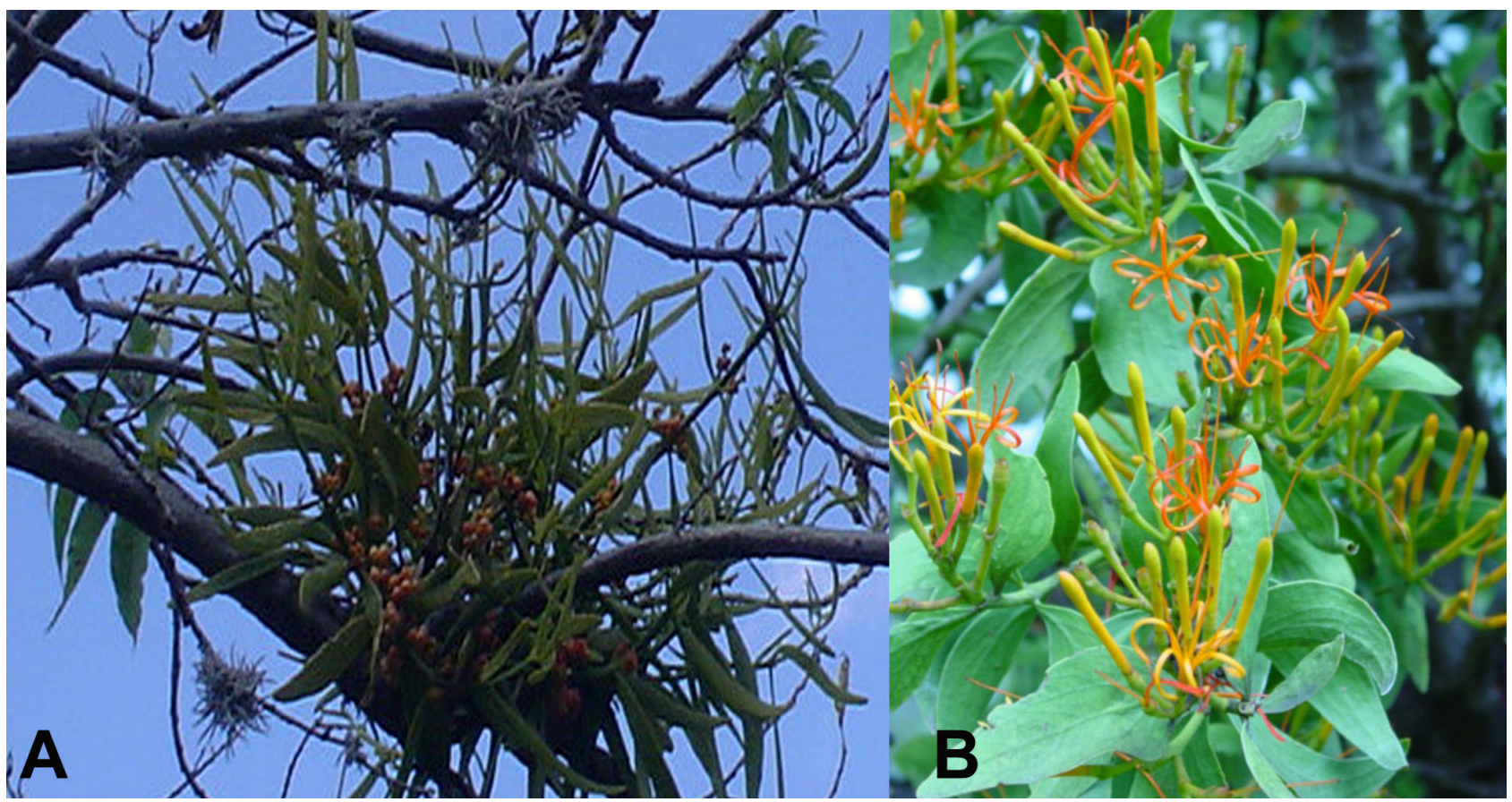

Figura 1. Plantas hemiparásitas. A, Phoradendron carneum creciendo sobre Ipomoea murucoides Roem. et Schult. (Convolvulaceae); B, Psittacanthus calyculatus creciendo sobre Fraxinus uhdei (Wenz.) Lingelsh. (Oleaceae).

almidón, solución de cloruro férrico al 10\% para confirmar la presencia de compuestos fenólicos y $\mathrm{HCl} 2 \mathrm{~N}$ para disolución de oxalato de calcio (Johansen, 1949; Curtis, 1986; Varela y Gurni, 1995; Ruzin, 1999). En todos los casos, las descripciones siguen los criterios y nomenclatura de Radford et al. (1974) y Font Quer (1982). Las fotografías se tomaron en un microscopio Zeiss Axiostar con una cámara digital Sony DSC-P32. Las preparaciones permanentes se localizan en el Laboratorio de Botánica de la Facultad de Ciencias Naturales, Universidad Autónoma de Querétaro.

\section{Resultados}

En cada género, las descripciones anatómicas corresponden a todas las especies que se estudiaron a menos que se indique lo contrario, ya que en algunos rasgos son pocas las diferencias entre las estructuras analizadas.

Anatomía de Phoradendron

Hoja. La hoja muestra un patrón de venación actinódromo o reticulado (Fig. 2A), es basinervada, con 3 a 5 venas de primer orden que corren paralelas desde la base y luego se ramifican, solamente la vena central alcanza el ápice. Las venas secundarias se ramifican repetidamente y se anastomosan formando una retícula, sin alcanzar el margen de la lámina. Las vénulas están modificadas en traqueidas dilatadas. Los idioblastos con drusas son abun- dantes y se distribuyen homogéneamente en toda la lámina (P. carneum) o se concentran justamente entre la retícula que forman las venas secundarias dejando el margen de la lámina libre de idioblastos ( $P$. forestierae y $P$. brachystachyum). Los elementos del xilema tienen paredes secundarias con engrosamientos anulares o helicoidales. En vista superficial los estomas se observan paracíticos, están en ambas superficies de la lámina y en el mismo nivel de la epidermis (Fig. 2B). Los tricomas, cuando están presentes, son simples, unicelulares y filiformes, se observan en ambas superficies de la lámina y alcanzan de 33 hasta $100 \mu \mathrm{m}$ de longitud. En sección transversal, la lámina (Fig. 2C) tiene una cutícula lisa de 4.3 a $8 \mu \mathrm{m}$ de espesor. La epidermis es uniseriada, lisa o papilosa, alcanza un espesor de 30 a $40 \mu \mathrm{m}$ y está conformada por células rectangulares a ovadas en vista transversal dispuestas de forma homogénea. El mesofilo es homogéneo y está conformado por células de parénquima de forma y tamaño variable. Los haces vasculares están dispuestos en forma lineal en el centro de la lámina, siendo el haz vascular central el de mayor tamaño; son colaterales abiertos, a veces con pequeños grupos de fibras asociados a ambos lados. Los idioblastos con drusas son frecuentes y se distribuyen en el centro de la lámina. Las drusas son de oxalato de calcio, se disuelven al reaccionar con $\mathrm{HCl} 2 \mathrm{~N}$. La reacción con lugol no evidencia la presencia de almidón en la hoja. La prueba con sudán III no revela presencia de substancias lipídicas. 
Mediante la reacción con cloruro férrico (10\%) se observa una moderada concentración de compuestos fenólicos en las células más externas del mesofilo. Las reacciones con azul de toluidina y con rojo de rutenio revelan moderada presencia de substancias pécticas en las células del mesofilo, excepto en P. forestierae.

El pecíolo (Fig. 2D), en vista transversal, tiene una cutícula lisa de 6 hasta $10 \mu \mathrm{m}$ de espesor. La epidermis es lisa o ligeramente papilosa, uniseriada y con células cuadradas a rectangulares en vista transversal y dispuestas de manera homogénea. Los tricomas, cuando presentes, son similares a los de la lámina. Un parénquima abundante rodea a 5 haces vasculares, el central es de mayor tamaño y son de tipo colateral abierto con casquetes conspicuos de fibras de paredes gruesas asociados a ambos lados. Estos haces vasculares se acomodan linealmente siguiendo la forma ovalada o arriñonada del pecíolo o forman una unidad central arriñonada (P. forestierae). Los elementos del xilema tienen paredes secundarias con engrosamientos anulares y helicoidales. Las drusas son frecuentes a abundantes en todo el parénquima y en ocasiones rodean los haces vasculares.

Tallo. En vista transversal (Figs. 2G, H) el tallo muestra cutícula conspicua, lisa a fuertemente papilosa, con espesores que van de $7 \mu \mathrm{m}$ de grosor en $P$. forestierae hasta $9 \mu \mathrm{m}$ en $P$. brachystachyum y $11 \mu \mathrm{m}$ en $P$. carneum. La epidermis es lisa o papilosa, uniseriada, de 30 a $40 \mu \mathrm{m}$ de espesor y está constituida por células rectangulares y ovoides en vista transversal de tamaño uniforme. Los tricomas son similares a los descritos para la hoja y se distribuyen en todo el tallo llegando a medir hasta $250 \mu \mathrm{m}$. El córtex consta de 7 a 8 estratos de células de parénquima, cuando están cerca de la epidermis son pequeñas y de forma rectangular a cuadrada y más grandes y redondas cuando se alejan de ésta, contiene abundantes idioblastos con drusas en $P$. carneum y $P$. forestierae o son escasos en P. brachystachium (Fig. 2E). Las braquiesclereidas (Figs. 2G-H, 3B) forman grupos de 2 a 7 células, son de forma isodiamétrica y se distribuyen en todo el córtex y a veces en la médula. En los tallos jóvenes con crecimiento secundario inicial (Fig. $2 \mathrm{G})$, el cilindro tiene haces vasculares colaterales, con grupos de fibras a ambos lados, que se distribuyen de manera concéntrica alrededor de una médula. El cámbium vascular forma un cilindro continuo y en el xilema los elementos de vaso tienen paredes con engrosamientos helicoidales y anulares (Fig. 2F). En tallos maduros no se observó peridermis ni epitelio epicuticular en ningún caso (Fig. 2H). En el xilema secundario la porosidad es difusa, los vasos se distribuyen en hileras radiales de 7 vasos o más, de contorno redondeado a radialmente aplanados. Están rodeados de numerosas fibras de lumen estrecho y pared gruesa. Los radios medulares son anchos y están formados por 2 a 5 hileras de células parenquimáticas alargadas radialmente, vistas en corte transversal, con drusas. La médula es parenquimatosa con células de forma y tamaño variable, los idioblastos con drusas son abundantes y, en ocasiones, las braquiesclereidas también son frecuentes (P. carneum). Las drusas son de oxalato de calcio. La reacción con lugol evidencia la presencia de almidón en el córtex, en el cilindro vascular y en la médula de $P$. carneum únicamente. La prueba con sudán III revela presencia de substancias lipídicas en algunas células del floema de los haces vasculares en $P$. forestierae. Mediante la reacción con cloruro férrico $(10 \%)$ se observa abundante concentración de compuestos fenólicos en el parénquima cortical y medular. Las reacciones con azul de toluidina y con rojo de rutenio revelan escasa presencia de substancias pécticas en el parénquima del córtex, en el cilindro vascular y en la médula.

Flor. Las flores se agrupan y están sostenidas y protegidas por artículos o brácteas, son unisexuales y las encierra y protege un perianto valvado (monoclamídeas). En una flor estaminada (Fig. 3A) el perianto, formado de 3 o 4 pétalos, encierra una cavidad floral soportada por una traba vascular simple. En el perianto se observa una cutícula conspicua, la epidermis es uniseriada y sus células son ligeramente cuadradas. Debajo de la epidermis y hacia el interior el resto del tejido es parénquima con células de forma y tamaño variable que corresponde a la pared de alguno(s) de los pétalos. Tanto en la epidermis como en el parénquima hay abundantes idioblastos con drusas. Los tricomas, cuando presentes, son filiformes y alcanzan $75 \mu \mathrm{m}$ de longitud. En el interior de la cavidad floral se observan 2 anteras de flores distintas y al centro un pistilodio conformado por tejido parenquimático. En la base del pistilodio hay un tejido con la coloración del citoplasma más intensa que probablemente corresponde a un disco nectarífero. Las anteras son sésiles, biloculares y abren por poros, la epidermis es uniseriada y sus células son periclinalmente alargadas y con paredes gruesas, el endotecio está conformado por un estrato de células anticlinalmente alargadas y de paredes engrosadas, el tapete no se observa, seguramente ha degenerado. Los granos de polen (Fig. 3C), en vista polar, se observan de circulares a ligeramente triangulares, tricolporados con los colpos constreñidos en el ecuador, la exina es ligeramente granular a verrugosa, en vista ecuatorial son circulares. La flor carpelada (Fig. 3D) es un pequeño ovario unilocular rodeado por 2 a 3 pétalos, en el centro se observa un estilo corto con un estigma no diferenciado, no tiene anteras rudimentarias. En el centro de la flor y en la base del pequeño estilo recto se observan células con coloración más oscura, probablemente corresponden al pequeño disco anular del cual se origina el estilo. Esta flor está vascularizada de manera similar a la flor estaminada con la salvedad de que tiene varios haces vasculares adicio- 


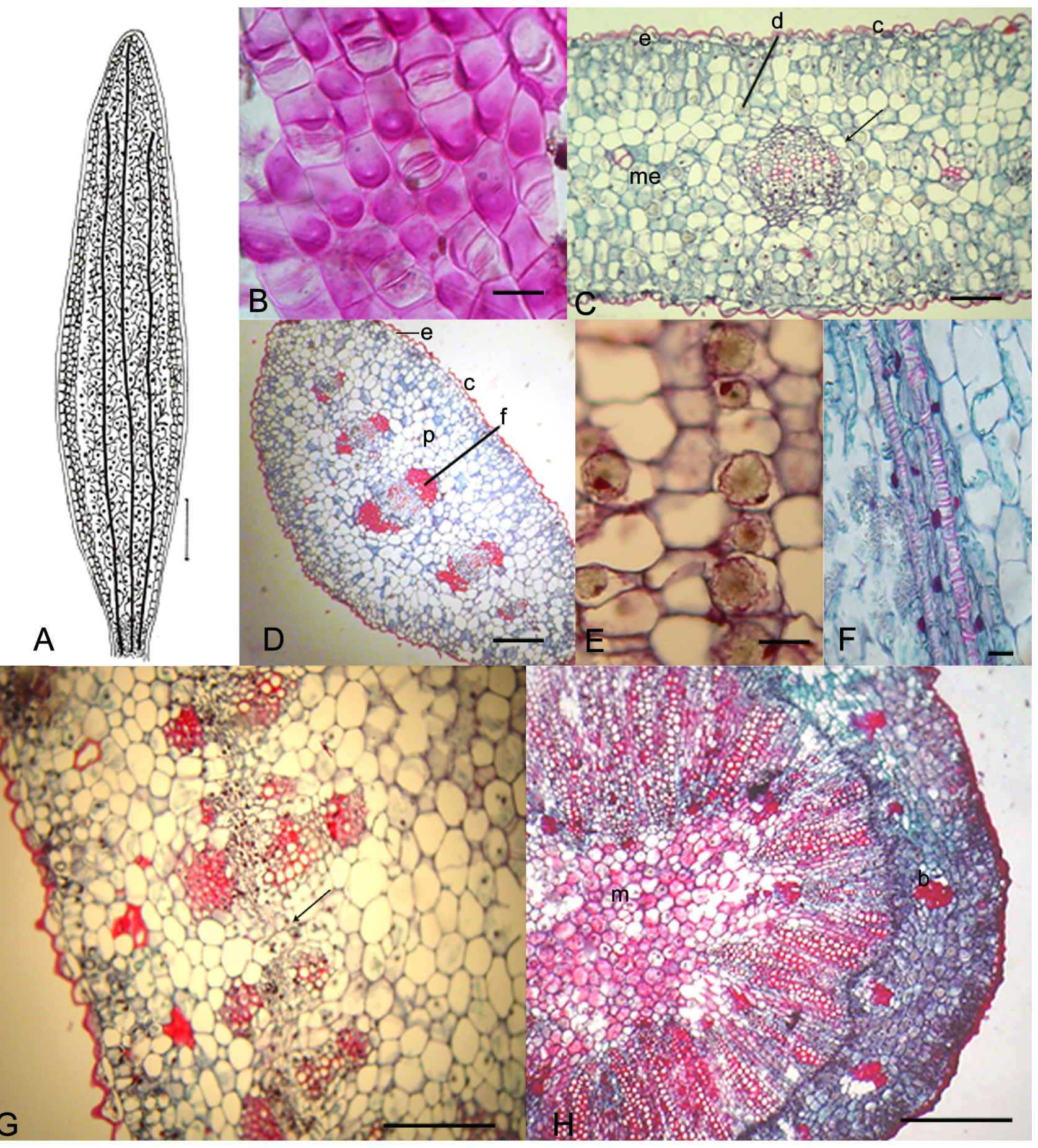

Figura 2. Anatomía foliar y caulinar de Phoradendron. A, Phoradendron forestierae; hoja diafanizada. B, Phoradendron carneum, epidermis con estomas (e) parasíticos, vista en superfice; C, Phoradendron carneum, corte transversal de lámina; D, Phoradendron carneum, corte transversal de pecíolo; E, Phoradendron carneum, drusas; F, Phoradendron brachystachym, corte longitudinal de tallo; G, H. Phoradendron forestierae, corte transversal de tallo; b, braquiesclereida, c, cutícula; d, drusa; e, epidermis; f, fibras; m, médula; me, mesofilo; p, parénquima. La flecha en $\mathrm{C}$ señala el haz vascular y en $\mathrm{G}$ y $\mathrm{H}$ señala el cámbium vascular interfascicular. Escala: $\mathrm{A}=$ $4.2 \mathrm{~mm} ; \mathrm{B}, \mathrm{F}=60 \mu \mathrm{m} ; \mathrm{C}, \mathrm{G}=200 \mu \mathrm{m} ; \mathrm{D}=300 \mu \mathrm{m} ; \mathrm{E}=63 \mu \mathrm{m} ; \mathrm{H}=450 \mu \mathrm{m}$. 
nales dispuestos en el centro y de manera concéntrica. La epidermis de esta flor es uniseriada, papilosa sobre todo en la parte basal que se observa libre del artículo, en la parte superior de los pétalos está rodeada por una cutícula más conspicua. El resto del tejido es parénquima con células de forma y tamaño variable. Los idioblastos con drusas son abundantes en toda la flor, a veces las braquiesclereidas también son frecuentes (Fig. 3B). El artículo que sostiene y agrupa las flores carpeladas tiene epidermis uniseriada y papilosa con cutícula delgada y los tricomas cuando presentes son filiformes; la vascularización es igual que en la flor, el resto del tejido es un parénquima de células grandes y también se observan braquiesclereidas y drusas.

Fruto. La baya, generalmente blanquecina, está provista de una cutícula lisa, conspicua, que alcanza 10 a $12 \mu \mathrm{m}$ de espesor. La epidermis (Figs. 3E-F) es uniseriada, papilosa, de células rectangulares, alargadas, que se disponen de manera homogénea. Los tricomas, cuando presentes, son simples y filiformes. El tejido subepidérmico, que junto con la epidermis constituye la pared externa del fruto (exocarpo), es parénquima y está conformado por 6 hasta 15 estratos de células alargadas y en ocasiones esféricas, las drusas y las braquiesclereidas son abundantes. Las braquiesclereidas están en grupos de 2 a 8 células isodiamétricas. Las braquiesclereidas están ausentes en $P$. forestierae. En $P$. forestierae se observan haces vasculares en la parte más interna del exocarpo (Fig. 3F). Hacia el interior, la viscina, tejido viscoso especializado que rodea a la semilla, alcanza espesores de hasta $1.7 \mathrm{~mm}$, sus células son radialmente alargadas, tienen la pared delgada y suelen ser más pequeñas cuando están cerca del exocarpo y más grandes cuando se alejan de él. Esta viscina, en su cara interna se adhiere al endocarpo y a veces se contrae longitudinalmente. La viscina, que ocupa el mesocarpo, comprende el $80-90 \%$ del fruto. Hacia el interior se observa un anillo concéntrico de tejido vascular que rodea a la semilla (embrión y endospermo). La reacción con lugol evidencia la presencia de almidón solamente en el endospermo de la semilla. La prueba con sudán III revela escasa cantidad de substancias lipídicas en algunas células de la parte externa del exocarpo. Mediante la reacción con cloruro férrico $(10 \%)$ no se observa presencia de compuestos fenólicos. Las pruebas con azul de toluidina y con rojo de rutenio revelan abundante cantidad de substancias pécticas en todo el fruto, concentrándose en el tejido víscido y en el exocarpo.

Anatomía de Psittacanthus

Hoja. La hoja tiene un patrón de venación actinódromo reticulado con 3 a 5 venas de primer orden que corren paralelas desde la base y luego se ramifican, solamente la vena central alcanza el ápice. Las venas laterales o secundarias se ramifican repetidamente (Fig. 4A), se anastomosan para formar una retícula pero no llegan al margen de la lámina. Las venas secundarias tienen sus terminaciones modificadas en traqueidas dilatadas conspicuas (Fig. 4B). Los idioblastos con drusas son escasos en $P$. calyculatus y están ausentes en P. palmeri. En $P$. calyculatus, además de las drusas típicas, se observan otros cristales prismáticos con un núcleo oscuro y varios brazos o ramas (Figs. 4A-C) que se encuentran en el mesofilo, principalmente en el centro y la base de la lámina. Estos cristales también son de oxalato de calcio. Los elementos del xilema tienen paredes secundarias con engrosamientos anulares y helicoidales $(P$. palmeri) y en algunas venas secundarias son reticulares ( $P$. calyculatus). En vista superficial los estomas son paracíticos (Fig. 4D), están presentes en ambas superficies de la lámina y en el mismo nivel que las células epidérmicas. En corte transversal de la lamina, la cutícula es lisa o rugosa en $P$. palmeri (Fig. 4E), en P. calyculatus es lisa, con 2 a $3 \mu \mathrm{m}$ de espesor. La epidermis es uniseriada, lisa, está conformada por células rectangulares en vista transversal achatadas en los bordes, de 20 a $40 \mu \mathrm{m}$ de espesor. Los tricomas están ausentes. El mesofilo es isobilateral (Figs. 4F, G), con parénquima clorofílico de 2 estratos de células alargadas anticlinalmente sobre ambas epidermis. Hacia el centro de la lámina el parénquima tiene células de forma y tamaño variable y no exhibe espacios de aire (excepto P. palmeri). Los haces vasculares están dispuestos en forma lineal y en el centro de la lámina, siendo el haz vascular central el de mayor tamaño, todos son colaterales abiertos y no tienen casquetes de fibras. En el xilema, sus elementos tienen paredes secundarias con engrosamientos anulares y helicoidales ( $P$. palmeri) y en algunas venas secundarias son de tipo reticular ( $P$. calyculatus). Las drusas y los cristales prismáticos son de oxalato de calcio. La reacción con lugol no evidencia la presencia de almidón. La prueba con sudán III revela escasa cantidad de substancias lipídicas en algunas células alrededor de los haces vasculares en P. calyculatus. Mediante la reacción con cloruro férrico $(10 \%)$ se observa abundante concentración de compuestos fenólicos en $P$. calyculatus, no así en $P$. palmeri donde dichos compuestos son escasos en algunas células del parénquima clorofílico. Las reacciones con azul de toluidina y con rojo de rutenio no revelan presencia de substancias pécticas.

El pecíolo, en corte transversal, tiene cutícula lisa (P. calyculatus) o rugosa (P. palmeri) con 5 a $7 \mu \mathrm{m}$ de espesor. La epidermis es uniseriada. Los tricomas están ausentes. Algunas veces (en P. palmeri), el pecíolo muestra algunos surcos en la cara adaxial. Un parénquima abundante rodea los haces vasculares, y sus células son de tamaño y forma variable. Los haces vasculares, general- 

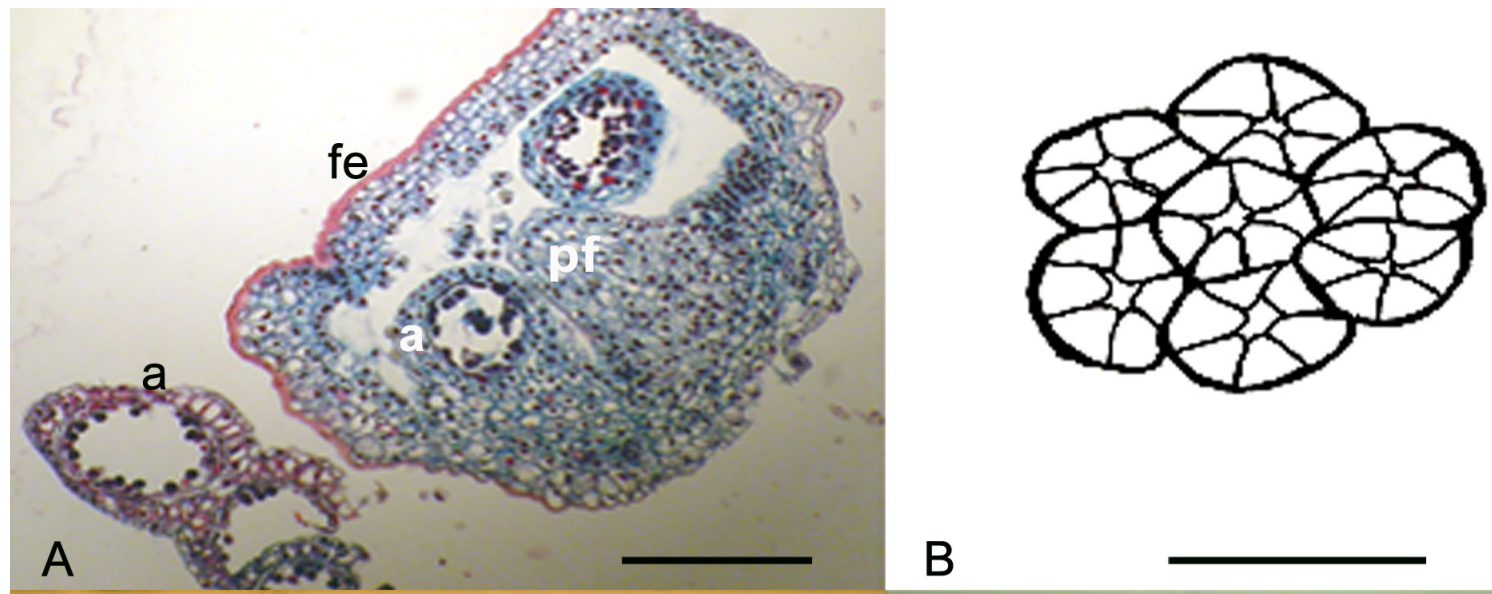

\section{B}

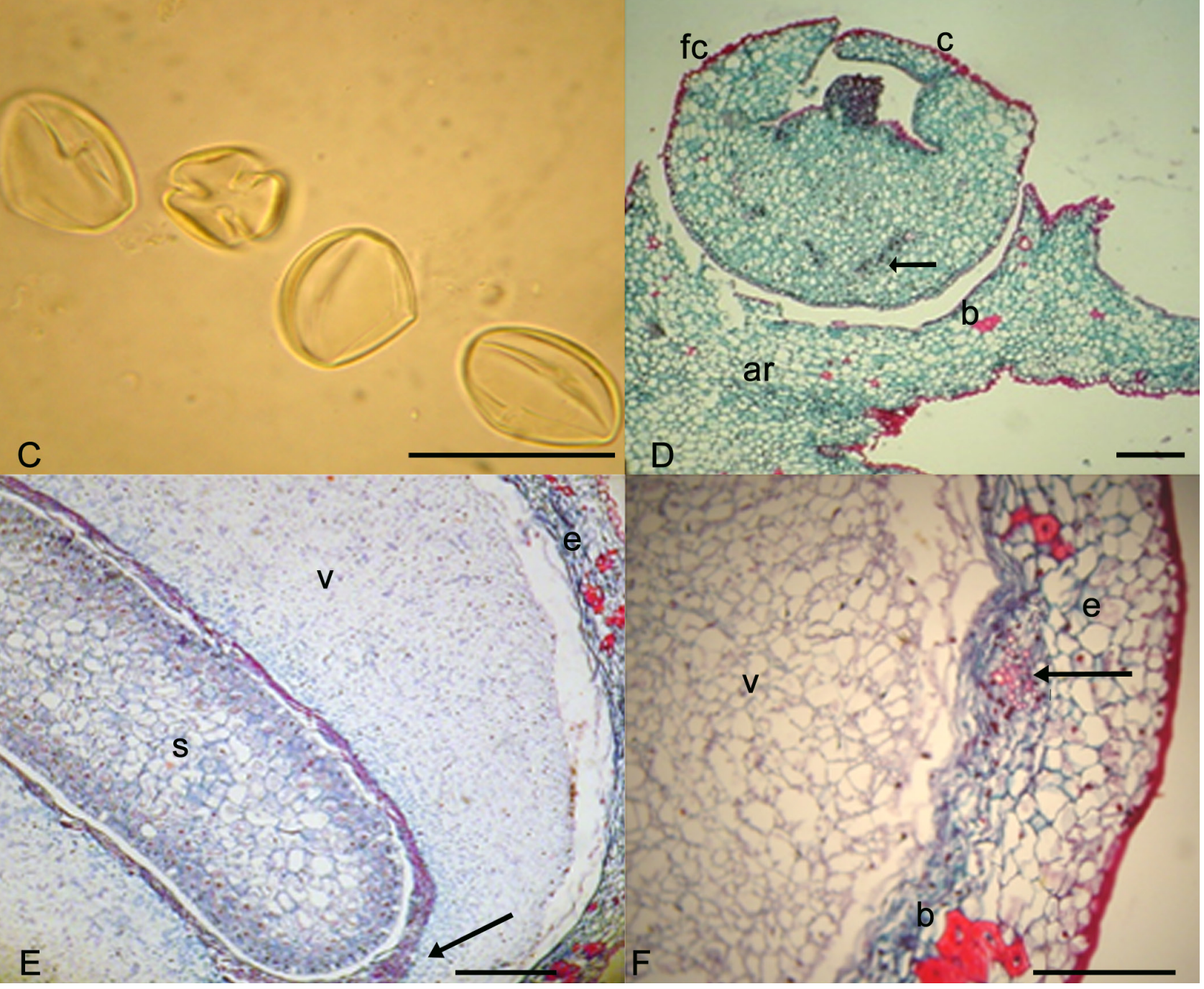

Figura 3. Anatomía reproductiva de Phoradendron. A, Phoradendron forestierae, flor estaminada; B, detalle de las braquiesclereidas. C, Phoradendron forestierae, granos de polen. D, Phoradendron carneum, sección longitudinal de la flor carpelada; E-F, Phoradendron carneum, corte longitudinal de fruto. Estructuras: a, antera; ar, artículo; b, braquiesclereida, c, cutícula; e, exocarpo; fc, flor carpelada; fe, flor estaminada; pi, pistilodio; s, semilla, v, viscina. La flecha en E-F señala un haz vascular. Escala: $A=100 \mu \mathrm{m} ; \mathrm{B}=67 \mu \mathrm{m} ; \mathrm{C}=65$ $\mu \mathrm{m} ; \mathrm{D}=817 \mu \mathrm{m} ; \mathrm{E}=200 \mu \mathrm{m}: \mathrm{F}=500 \mu \mathrm{m}$. 


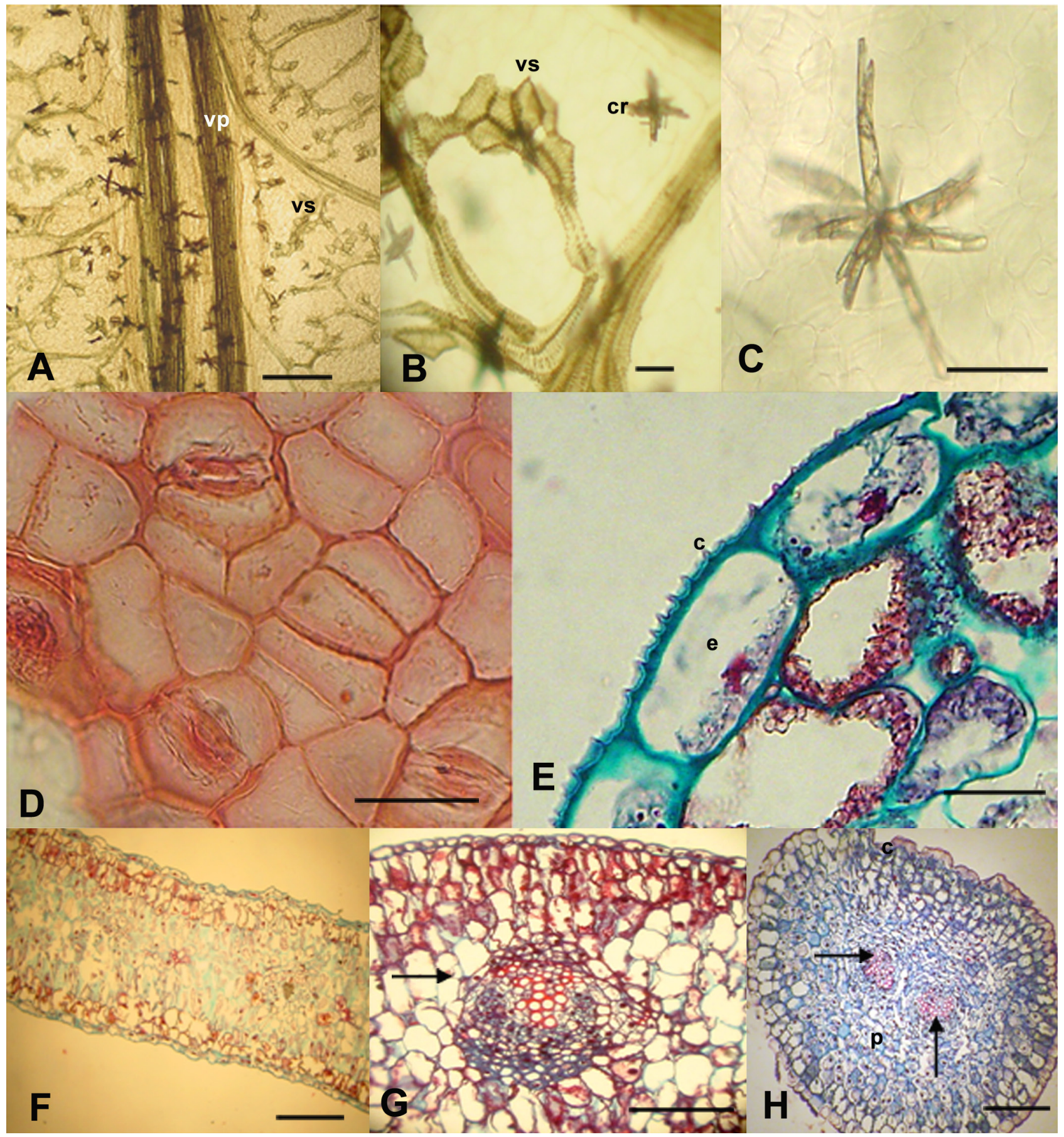

Figura 4. Anatomía foliar y caulinar de Psittacanthus. A-C, Psittacanthus calyculatus, hoja diafanizada; C, detalle del cristal prismático. D, Psittacanthus palmeri, epidermis con estomas parasíticos, vista en superficie; E-F, Psittacanthus palmeri, corte transversal de lámina; G, Psittacanthus calyculatus, corte transversal de lámina; H, Psittacanthus palmeri, corte transversal de pecíolo. Estructuras: c, cutícula; cr, cristal prismático; e, epidermis; p, parénquima; vp, vena primaria; vs, vena secundaria. La flecha en $\mathrm{G}$ y $\mathrm{H}$ señala un haz vascular. Escala: $A, G=300 \mu \mathrm{m} ; \mathrm{B}=25 \mu \mathrm{m} ; \mathrm{C}, \mathrm{D}=30 \mu \mathrm{m} ; \mathrm{E}=60 \mu \mathrm{m} ; \mathrm{F}=450 \mu \mathrm{m} ; \mathrm{H}=500 \mu \mathrm{m}$. 
mente de 2 a 4, son de tipo colateral abierto, sin casquetes de fibras y se acomodan de manera contigua formando una unidad central (Fig. 4H). Los elementos del xilema tienen paredes secundarias con engrosamientos helicoidales y reticulares. Las drusas están ausentes. Las braquiesclereidas son abundantes en $P$. calyculatus y se distribuyen en todo el pecíolo o están ausentes en P. palmeri.

Tallo. En corte transversal (Figs. 5A-C, E), el tallo tiene cutícula lisa, en algunas porciones es fuertemente rugosa, con espesores de $8 \mu \mathrm{m}$ en $P$. calyculatus, o menos en $P$. palmeri. La epidermis es uniseriada con estomas de tipo paracítico. En P. calyculatus, se conserva la epidermis con células cuadradas a rectangulares que alcanzan un espesor de $20 \mu \mathrm{m}$, mientras que en P. palmeri se observa una peridermis con 3 a 4 estratos de células suberosas (Figs. 5B, C). Los tricomas están ausentes. El córtex tiene de 12 a 18 estratos de células isodiamétricas en vista transversal, más pequeñas cuando están cerca de la epidermis y más grandes cuando se alejan de ésta. No hay drusas. Las braquiesclereidas se arreglan en grupos de 2 a 7 células isodiamétricas, distribuyéndose en los estratos más externos del córtex. En las 2 especies, secciones de tallo joven (Figs. 5A, B) con crecimiento secundario inicial muestran un cilindro central formado por 12 a 26 haces vasculares colaterales abiertos, donde el xilema tiene paredes secundarias con punteaduras alternas (Fig. 5D) en sus elementos. En los tallos maduros, el xilema secundario tiene porosidad difusa, los vasos se distribuyen solitarios o en grupos (P. calyculatus) (Fig. 5E), o bien, en hileras radiales de 6 vasos o más (P. palmeri), son redondos a radialmente aplanados en contorno; los elementos traqueales tienen paredes secundarias con engrosamientos del xilema helicoidal y anular. Las fibras libriformes son de paredes bastante gruesas. Los radios medulares son multiseriados, el parénquima axial es difuso y no se observan drusas en sus células. En el floema hay algunas fibras en casquetes. La médula está conformada por parénquima cuyas células isodiamétricas son más grandes en el centro, no hay drusas pero las braquiesclereidas son frecuentes en ambas especies. La reacción con lugol no evidencia la presencia de almidón. La prueba con sudán III revela escasa presencia de sustancias lipídicas en algunas células del cilindro vascular y de la parte externa del córtex y en la médula. Mediante la reacción con cloruro férrico (10\%) se observa abundante concentración de compuestos fenólicos en todas las regiones del tallo de ambas especies. Las reacciones con azul de toluidina y con rojo de rutenio revelan moderada presencia de substancias pécticas en el parénquima cortical y en la médula, en el cilindro vascular la presencia de estas substancias es escasa.

Flor. Las flores son hermafroditas y tienen un perianto bien diferenciado (diclamídeas). En una vista longitudinal de la flor se observa el cáliz con cutícula muy delgada y epidermis uniseriada, el resto del tejido es parénquima cuyas células, que son más grandes que las epidérmicas, son periclinalmente alargadas y están arregladas de manera lineal siguiendo el eje de la flor, los haces vasculares no se observaron. Las drusas y los tricomas están ausentes. La corola, con cutícula extremadamente delgada, tiene también epidermis uniseriada, el cuerpo de la corola es parénquima cuyas células son de forma y tamaño variable. Las drusas y los tricomas están ausentes. El ovario exhibe epidermis uniseriada con células rectangulares y tejido de parénquima con células de forma y tamaño variable. En la base del ovario (flecha) se observa un tejido conformado por 3 a 6 estratos de células con paredes gruesas y fuertemente lignificadas (Fig. 6A). El estilo es rollizo, cilíndrico y alargado, tiene la epidermis uniseriada con células rectangulares siguiendo el plano del corte, un parénquima de células rectangulares y alargadas y las braquiesclereidas son frecuentes en la base. En todos los verticilos florales, excepto el cáliz, los engrosamientos de las paredes de los elementos del xilema son helicoidales, rara vez anulares. Las anteras (Fig. 6B) que abren longitudinalmente, tienen epidermis uniseriada y sus células son de forma y tamaño variable, el endotecio está conformado por 2 a 3 estratos de células, el tapete no se observa por degeneración del mismo. Los sacos polínicos están separados por un tejido de varias capas de células parenquimáticas de paredes delgadas similares a las del endotecio que conforman un conectivo. Los granos de polen (Fig. 6C), en vista polar, son de forma fuertemente triangular, tricolporados, anguloaperturados, los colpos con márgenes lisos y rectilíneos y su ornamentación es lisa a ligeramente escabrosa, en vista ecuatorial son más o menos esféricos a elípticos.

Fruto. La baya, generalmente de color negruzco, muestra cutícula lisa, con espesor cercano a $5 \mu \mathrm{m}$. La epidermis es uniseriada y está conformada por células rectangulares. Los tricomas están ausentes. El exocarpo posee de 4 a 8 estratos de células alargadas (Fig. 6D), casi rectangulares o en ocasiones circulares donde las drusas y las braquiesclereidas están ausentes. Los haces vasculares están dispuestos de manera concéntrica alrededor de la semilla. La viscina, tejido viscoso que rodea propiamente a la semilla, está formada por una capa externa o viscina vesicular, alcanzando espesores de hasta $1.4 \mathrm{~mm}$, sus células están radialmente alargadas y tienen pared delgada, suelen ser pequeñas cerca del exocarpo y más grandes cuando se alejan de éste (Fig. 6D). Al interior, la viscina principal que rodea completamente al embrión está conformada por varios estratos de células isodiamétricas. En P. palmeri, esta viscina es conspicua, se ensancha de la parte media hacia uno de los extremos y forma una capucha que rodea completamente al embrión y alcanza los $550 \mu \mathrm{m}$ de espe- 


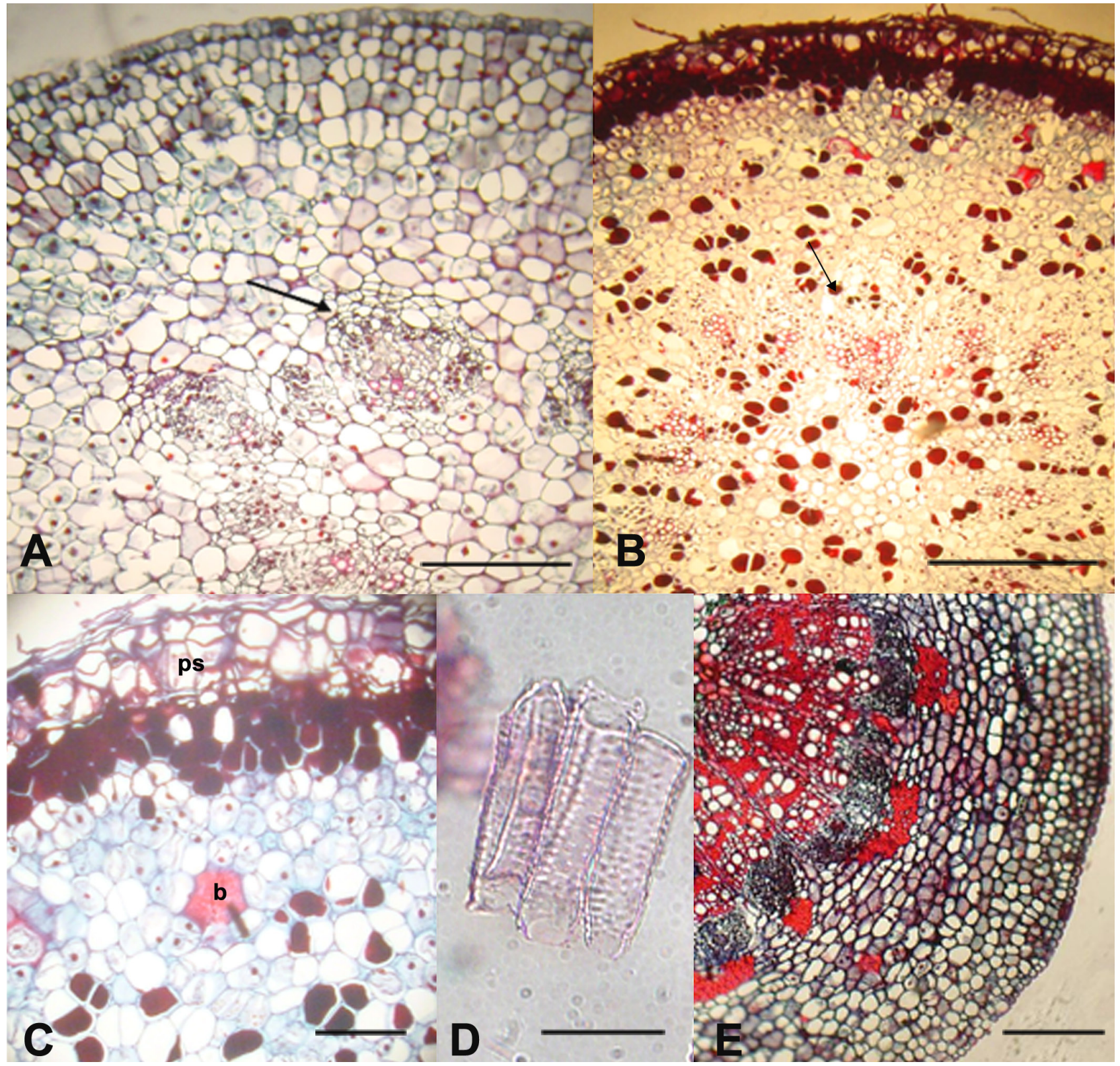

Figura 5. Anatomía caulinar de Psittacanthus. A, Psittacanthus calyculatus, corte transversal de tallo con crecimiento secundario inicial; B-C, Psittacanthus palmeri, corte transversal de tallo; D, Psittacanthus calyculatus, disociado del xilema; E, Psittacanthus calyculatus, corte transversal de tallo, con crecimiento secundario avanzado. Estructuras: b, braquiesclereida, ps, peridermis suberosa, la flecha en A y B señala un haz vascular. Escala: $A=340 \mu \mathrm{m} ; \mathrm{B}, \mathrm{E}=400 \mu \mathrm{m} ; \mathrm{C}=500 \mu \mathrm{m}, \mathrm{D}=60 \mu \mathrm{m}$.

sor. La viscina ocupa casi el $95 \%$ del fruto. El centro del fruto está ocupado por la semilla. La reacción con lugol evidencia la presencia moderada de almidón en la semilla (endospermo). La prueba con sudán III revela escasa presencia de substancias lipídicas en el exocarpo. Mediante la reacción con cloruro férrico $(10 \%)$ se observa abundante concentración de compuestos fenólicos en el exocarpo y en la parte más interna del fruto, en la viscina principal.
Las reacciones con azul de toluidina y con rojo de rutenio revelan abundante cantidad de substancias pécticas en todo el fruto, con mayor concentración en el tejido víscido.

\section{Discusión}

La anatomía vegetativa y reproductiva de Phoradendron y Psittacanthus muestra algunas diferencias 


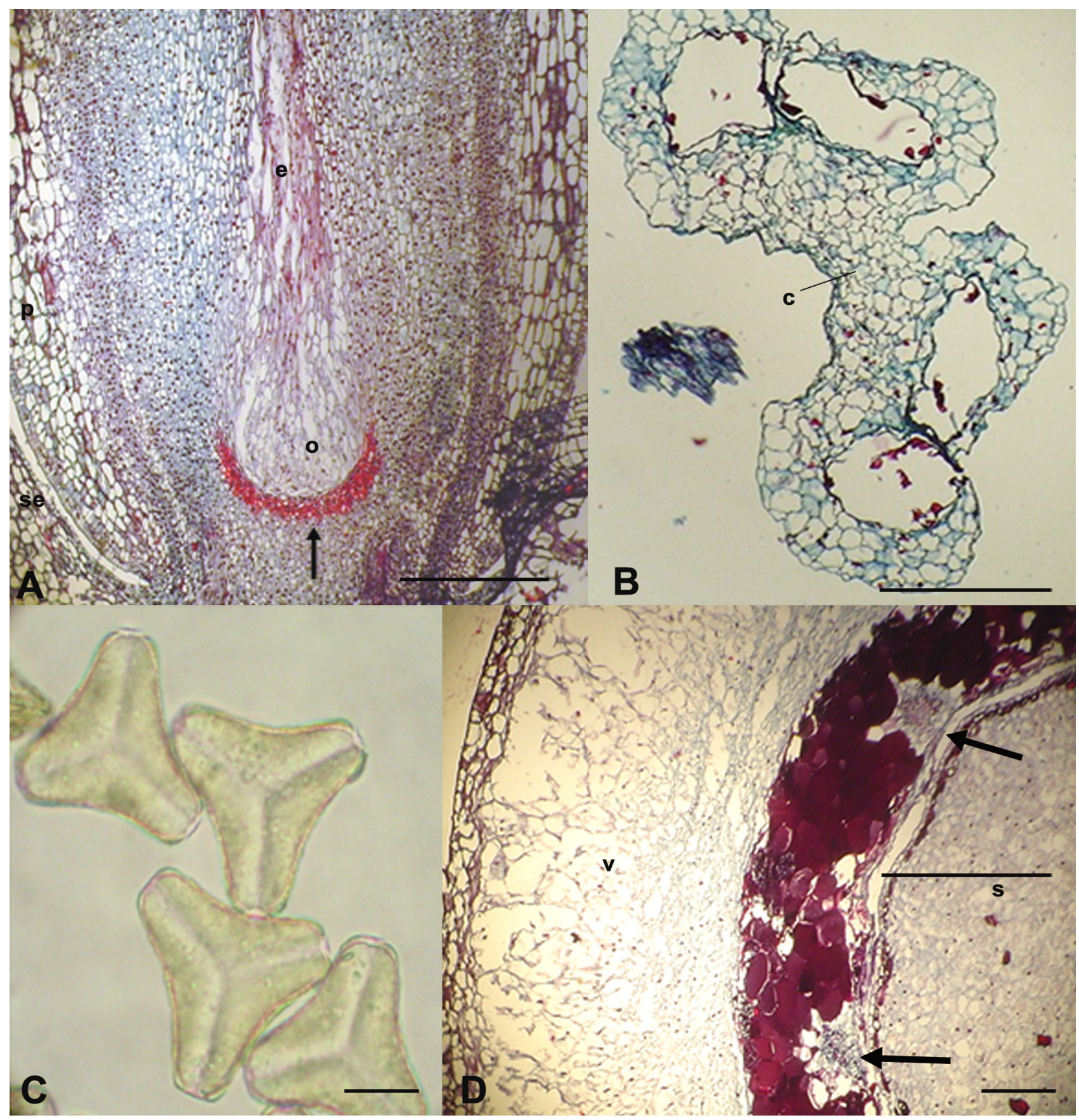

Figura 6. Anatomía reproductiva de Psittacanthus palmeri. A, corte longitudinal de la base de la flor; B, corte transversal de antera; C, granos de polen; D, corte longitudinal de fruto. Estructuras: c, conectivo; e, estilo; o, ovario; p, pétalo; s, semilla; se, sépalo; v, viscina. La flecha en A señala la pélvis y en D los haces vasculares. Escala: $A=500 \mu \mathrm{m}, \mathrm{B}=60 \mu \mathrm{m}, \mathrm{C}=340 \mu \mathrm{m}, \mathrm{D}=400 \mu \mathrm{m}$.

estructurales entre sus especies. Dichas diferencias así como la comparación de los caracteres anatómicos descritos aquí con los señalados previamente para otras especies de muérdago se discuten a continuación.

Hoja. Las especies estudiadas tienen algunos caracteres comunes estables que comparten con otros representantes de Viscaceae y Loranthaceae, como las hojas basinervadas donde la vena principal central es la única que alcanza el ápice, los estomas paracíticos y las venas secundarias con terminaciones modificadas en traqueidas dilatadas (Metcalfe y Chalk, 1950; Sosa, 2003; Varela y Gurni, 2003; Varela et al., 2004; Dettke y Milaneze-Gutierre, 
2007; Varela et al., 2008). Estas pequeñas terminaciones de las venas secundarias consisten de traqueidas abultadas para almacén y parecen ser un rasgo de la mayoría de las especies de muérdago, como también lo señala Kuijt (2003). Los idioblastos con drusas típicas, abundantes y conspicuos en las especies de Phoradendron, coincide con lo descrito por Sosa (2003) y Varela et al. (2004). Además de las drusas típicas se han descrito algunos cristales amorfos en el mesofilo de Phoradendron mucronatum (Dettke y Milaneze-Gutierre, 2007); sin embargo, los cristales con un núcleo oscuro y con varios brazos o ramas bien definidas que se observan en Psittacanthus calyculatus no se han descrito en otras especies de muérdago. Estos cristales podrían interpretarse como un artefacto resultante del proceso de la técnica; no obstante, en repetidas ocasiones se hicieron pruebas para comprobar su naturaleza química. En todos los casos, los cristales se disolvieron al reaccionar con $\mathrm{HCl} 2 \mathrm{~N}$.

En las especies de Phoradendron, la lámina en vista transversal muestra cutícula gruesa y lisa como lo refieren Sosa (2003) y Dettke y Milaneze-Gutierre (2007) para otras especies mexicanas y sudamericanas, no obstante, la cutícula papilosa solamente se había descrito en pecíolo de P. mucronatum (Dettke y Milaneze-Gutierre, 2007) y en tallo de $P$. liga (Varela et al., 2008). La cutícula estriada de algunas especies argentinas de Phoradendron (Sosa, 2003) no se observó aquí. Aunque Sosa (2003) señala que en la familia Loranthaceae la cutícula suele ser delgada, la cutícula rugosa de Psittacanthus palmeri no se ha registrado en otras especies. La epidermis uniseriada es un rasgo común en otras especies de muérdago. Los estomas están dispuestos al mismo nivel que las células de la epidermis, coincidiendo con Metcalfe y Chalk (1950). El mesofilo isobilateral que se observó en las 2 especies mexicanas de Psittacanthus analizadas es un rasgo que está presente también en Psittacanthus cordatus y Ligaria cuneifolia (Varela y Gurni, 1995; Varela et al., 2001; Varela y Gurni, 2003). El mesofilo homogéneo que se observó en las 3 especies mexicanas de Phoradendron solamente se ha indicado en la especie sudamericana Phoradendron mucronatum (Dettke y Milaneze-Gutierre, 2007) y en el muérdago europeo Viscum album (Varela y Gurni, 1995). A pesar de que Sosa (2003) y Varela y Gurni (2003) describen, en Psittacanthus cordatus y en otros géneros de la familia Loranthaceae, los haces vasculares de la lámina con casquetes de fibras del xilema y floema, su descripción no corresponde con lo que se observó aquí en Psittacanthus calyculatus y P. palmeri, pues los casquetes de fibras asociadas a los haces vasculares están ausentes. La anatomía de la hoja de P. palmeri agrega información relevante para el conocimiento de esta especie que presenta estacionalidad decídua (Kuij, 2009), condición rara entre las especies de Psittacanthus.
En el pecíolo, la cutícula muestra el mismo patrón que en la lámina; en Psittacanthus es más delgada y rugosa. Dettke y Milaneze-Gutierre (2007) estudiaron el pecíolo de Phoradendron mucronatum y señalan una cutícula espesa y una epidermis papilosa, coincidiendo con lo que se observa aquí en las especies analizadas de Phoradendron. Los casquetes de fibras de paredes gruesas en ambos lados de los haces vasculares es un rasgo común en otras especies de muérdago como Phoradendron crassifolium, Viscum album (Metcalfe y Chalk, 1950) y en varias especies sudamericanas de Phoradendron (Sosa, 2003; Dettke y Milaneze-Gutierre, 2007). Sin embargo, este carácter no se observó en el pecíolo de las especies de Psittacanthus que se estudiaron ni tampoco en la lámina de la hoja como lo señalan Varela y Gurni (2003) para Psittacanthus cordatus. Los idioblastos con braquiesclereidas solamente se observaron en el pecíolo de Psittacanthus calyculatus.

Tallo. En corte transversal, el tallo generalmente tiene forma circular. En Psittacanthus calyculatus se observa angular en tallos maduros pero en tallos jóvenes también es circular, lo cual coincide con lo que señalan Dettke y Milaneze-Gutierre (2007) en Phoradendron mucronatum pero contrariamente a lo que observan Varela y Gurni (2003) en Psittacanthus cordatus. La cutícula sigue el mismo patrón que en la hoja, es conspicua y más gruesa en las especies de Phoradendron, en Psittacanthus calyculatus es más delgada y rugosa. Metcalfe y Chalk (1950) y Wilson y Calvin (2003) describen el desarrollo de un epitelio cuticular adicional que protege la epidermis en tallos viejos de todos los géneros de Viscaceae y algunos de Loranthaceae, no obstante, aquí no se observó este tejido. La peridermis suberosa de Psittacanthus palmeri solamente se ha observado en Psittacanthus cordatus (Varela y Gurni, 2003), no obstante, este rasgo no se observó en Psittacanthus calyculatus ni en las especies de Phoradendron estudiadas, coincidiendo con Kuijt (2003) y Dettke y Milaneze-Gutierre (2007) quienes señalan que el corcho en tallo de Phoradendron no se desarrolla. El córtex, aunque muestra células de diferente tamaño y forma, nunca es heterogéneo como en Ligaria cuneifolia (Varela et al., 2001) y en Psittacanthus cordatus (Varela y Gurni, 2003). En las especies estudiadas aquí, las células son cuadrangulares y se vuelven redondeadas en las proximidades con el cilindro vascular, en coincidencia con lo que observan Varela y Gurni (1995) en Viscum album. La presencia de drusas parece ser un rasgo común del género Phoradendron, no así para Psittacanthus pues las drusas en el tallo solamente se han registrado en Psittacanthus cordatus (Varela y Gurni, 2003). Ligaria cuneifolia presenta astroesclereidas en el córtex (Varela y Gurni,1995; Varela et al., 2001; Varela y Gurni, 2003). Sin embargo, en las especies que se estudiaron aquí no se observan., lo que 
concuerda con las observaciones de Varela et al. (2004) y Dettke y Milaneze-Gutierre (2007) en Phoradendron liga y $P$. mucronatum respectivamente. Las braquiesclereidas se observaron tanto en las especies de Phoradendron como en las de Psittacanthus, un rasgo que también se registra en Phoradendron liga (Varela et al., 2004), en Viscum album (Varela y Gurni, 1995) y en otros géneros de muérdago (Metcalfe y Chalk, 1950). La disposición o el arreglo de los haces vasculares es similar a lo que se describe para el género Phoradendron y sus especies (Metcalfe y Chalk, 1950; Varela y Gurni, 1995; Ashworth y Dos Santos, 1997; Varela et al., 2001; Kuijt, 2003; Dettke y MilanezeGutierre, 2007). Las drusas en las células parenquimáticas de la médula es un rasgo común en las 3 especies de Phoradendron que se analizaron pero no así para las de Psittacanthus. Las braquiesclereidas se observan en la médula de Phoradendron carneum y Psittacanthus calyculatus; sin embargo, las esclereidas cristalíferas descritas en otros muérdagos sudamericanos como Psittacanthus cordatus (Varela y Gurni, 2003) y Ligaria cuneifolia (Varela y Gurni, 1995; Varela et al., 2001), no se observaron en ninguna de las especies analizadas.

Algunos rasgos en las hojas, pecíolos y tallos, como la cutícula gruesa, cutinizada, la peridermis con tejido suberoso y la presencia de tricomas, están asociados al xeromorfismo, permitiendo que la planta regule la pérdida de agua por transpiración y la protegen de una radiación solar excesiva. De las 5 especies estudiadas, las 3 especies de Phoradendron y Psittacanthus palmeri, aunque no están en contacto directo con el sol, habitan en ambientes que están sujetos a menor disponibilidad de agua. Estas especies muestran algunas características anatómicas que les confieren alguna adaptación relacionada con el xeromorfismo, como la cutícula gruesa, papilosa y cutinizada así como el arreglo de los vasos en largas hileras radiales y su elevado número, en concordancia con lo que señalan Carlquist (1975) y Ashworth y Dos Santos (1997) para otras especies. Psittacanthus calyculatus crece de manera abundante en ambientes cercanos a las áreas urbanas donde tienen mayor disponibilidad de agua, pero como prefieren las áreas abiertas, también tienen mayor radiación solar. Las drusas, las braquiesclereidas y las fibras ofrecen protección mecánica y protegen a la planta contra la herbivoría. Aunque Fahn et al. (1986) señalan la presencia de cristales en Viscum, Cannon (1901) en Phoradendron villosum y York (1909) en P. macrophyllum, las drusas que observamos en las células de parénquima radial de Phoradendron sólo han sido documentadas previamente por Ashworth y Dos Santos (1997) en 4 especies californianas de Phoradendron.

Flor. Los detalles anatómicos de las flores respecto al estilo y estigma y el patrón de vascularización coinciden en parte con lo que señalan Venturelli (1984b) y Kuijt (2003, 2009). En Psittacanthus todos los verticilos florales están vascularizados a excepción del cáliz. Este rasgo se describe también en Struthanthus vulgaris (Venturelli, 1984b) y es común en las Loranthaceae. En otros géneros de Loranthaceae, como Tripodanthus y Struthanthus, se señala en la pared de la antera la diferenciación de una capa intermedia de células parenquimáticas entre el endotecio y el tapete (Venturelli, 1981, 1983); no obstante, en las especies mexicanas de Psittacanthus que se analizaron no se distingue, posiblemente colapsó una vez que la antera maduró. La forma circular de los granos de polen de las especies de Phoradendron analizadas es similar a la del polen de $P$. californicum y $P$. serotinum que describe Kuijt (2003), quien además señala que estas especies tienen similitud con otras del Viejo Mundo del género Viscum. La forma y la ornamentación del polen de Psittacanthus que se describe aquí coinciden con lo que señala Kuij (2009) y con lo que describe Venturelli $(1981,1983)$ en los géneros Tripodanthus y Struthanthus. El conjunto de células con paredes lignificadas que se diferencian debajo del ovario de Psittacanthus calyculatus corresponde a lo que Venturelli (1983) señala como pelvis en Tripodanthus, en alusión a su forma de vaso o cuenco. Este tejido se forma durante el proceso de formación del gametofito femenino, impide el crecimiento intrusivo del saco embrionario, se observa también en distintas etapas de desarrollo del fruto y es una característica común en Loranthaceae (Venturelli, 1981, 1983).

Fruto. La estructura y la presencia y disposición de la viscina coincide en parte con lo que señala Kuijt (2003) para el género Phoradendron, sin embargo, la presencia de haces vasculares en la cara interna del exocarpo en Phoradendron forestierae no se ha señalado previamente y es algo inesperado dada la vascularización de la flor y la formación del exocarpo. La estructura interna del fruto de Psittacanthus no se ha documentado mucho, salvo lo poco que Kuijt (1967) analiza en $P$. schiedeanus. En Psittacanthus se observaron 2 tipos de viscina, una estratificada y predominante que rodea y cubre la mayor parte del embrión, y otra, la vesicular que se separa hacia uno de los extremos coincidiendo con Kuijt (2009). La zona parenquimática interna de células con paredes delgadas y vacuoladas que señala Venturelli (1983) en el fruto del género Tripodanthus corresponde seguramente a lo que Kuij (2009) y aquí se describe como viscina vesicular. La viscina le confiere ventajas a la planta porque le ayuda a la semilla a deslizarse a través del tracto digestivo del ave que funge como dispersor $y$, por otro lado, le permite a la semilla adherirse con facilidad a las ramas del hospedero y entonces podrá establecerse y generar otro individuo y/o colonizar nuevos hospederos. La cantidad de tejido viscoso 
es variable entre la especies de Psittacanthus y la viscina de tipo vescicular provee una cápsula protectora que permanece en su lugar hasta que se forma el haustorio (Kuij, 2009). Esta cápsula se rompe durante la germinación con la emergencia de las hojas jóvenes, por lo que seguramente dicha cápsula le confiere a la planta de una ventaja para adaptarse a ambientes secos. Por otra parte, la presencia de este tejido víscido en el fruto proporciona humedad a la semilla favoreciendo su germinación.

Pruebas histoquímicas. Las pruebas histoquímicas simples revelaron la presencia de algunos compuestos. El almidón, elemento común y abundante en tallos de otros muérdagos, como Ligaria cuneifolia y Viscum album (Varela y Gurni, 1995), solamente se detectó en el tallo de Phoradendron carneum con presencia moderada. Los compuestos lipídicos fueron escasos en 2 de las especies mexicanas que se analizaron, contrariamente a lo descrito en el parénquima tanto foliar como caulinar de algunas especies sudamericanas y europeas como Phoradendron mucronatum (Dettke y Milaneze-Gutierre, 2007), Ligaria cuneifolia y Viscum album (Varela y Gurni, 1995). Las sustancias pécticas en tallo y hoja fueron moderadas, mientras en el fruto estas sustancias son abundantes. Los compuestos fenólicos son abundantes en el parénquima foliar y caulinar de todas las especies analizadas y en el exocarpo del fruto de Psittacanthus calyculatus. La importancia de las sustancias pécticas y los compuestos fenólicos en la salud está ampliamente documentada y estas sustancias se asocian con las propiedades terapéuticas de muchas plantas, lo cual explica que algunas de estas especies hemiparásitas tengan un amplio uso en la medicina popular para tratar enfermedades como cáncer, diabetes, afecciones cardíacas por su acción hipocolesterolemiante, hipertensión, algunas afecciones en la piel, obesidad, entre otras (Rodríguez-Cruz et al., 2003; Varela et al., 2004; Carvantes-Badillo, 2006; Alonso-Castro et al., 2011). Por otra parte, la gran cantidad de drusas en la lámina de la hoja es un rasgo que, al menos en Phoradendron, podría limitar su uso medicinal, sin embargo, la presencia de drusas y de compuestos fenólicos protegen a la planta de la herbivoría.

Entre los caracteres anatómicos que permiten distinguir estos géneros destacan la abundancia de drusas, la cutícula y la epidermis lisa o papilosa, el mesofilo homogéneo y los haces vasculares de tipo colateral con grupos de fibras asociados a ambos lados, el exocarpo con haces vasculares en su capa más interna, la viscina ligeramente menor y el mucílago y los compuestos fenólicos tienen presencia moderada en Phoradendron, mientras que en Psittacanthus no hay drusas o son escasas, contiene unos cristales prismáticos con varios brazos o ramas, se observan cutícula rugosa y peridermis suberosa, el mesofilo es isobilateral, los haces vasculares no tienen fibras alrededor, el exocarpo no muestra haces vasculares, la viscina ocupa gran parte del fruto y las substancias pécticas y los compuestos fenólicos tienen mayor presencia.

\section{Agradecimientos}

A Robert W. Jones, quién amablemente revisó el resumen en inglés. A 3 revisores anónimos y a Teresa Terrazas, por sus observaciones que mejoraron sustancialmente este trabajo. Se reconoce y agradece el apoyo financiero de la Comisión Nacional Forestal a través de los proyectos CONAFOR-2004-C04-65 y CONAFOR-2007-AD-01.

\section{Literatura citada}

Alonso-Castro, A. J., M. L. Villarreal, L. A. Salazar-Olivo, M. Gómez-Sánchez, F. Domínguez y A. García-Carranca. 2011. Mexican medicinal plants used for cancer treatment: pharmacological, phytochemical and ethnobotanical studies. Journal of Ethnopharmacology 133:945-972.

Ashworth, V. T. E. M. 1997. Transectional anatomy of leaves and young stems of mistletoe genus Phoradendron Butt. (Viscaceae). American Journal of Botany 84:174-175.

Ashworth, V. E. T. M. y G. Dos Santos. 1997. Wood anatomy of four Californian mistletoe species (Phoradendron, Viscaceae). IAWA Journal 18:229-245.

Calzado-Flores, F. C., E. G. Gómez L, M. G. Sánchez S., M. A. Echávarri-Guzmán, G. Aguilar-Cuestas y A. L. Robledo H. 2005. Contribución al estudio fitoquímico de Phoradendron tomentosum de la región norte de Nuevo León. Centro de Investigación Biomédica delNoreste, IMSS y Departamento de Química, Instituto Tecnológico y de Estudios Superiores de Monterrey, Campus Monterrey. Revista Salud Pública y Nutrición 8:1-2.

Cannon, W. A. 1901. The anatomy of Phradendron villosum Nutt. I. Bulletin Torrey of Botany Club 28:374-390.

Carlquist, S. 1975. Ecological factors strategies of xylem evolution. University of California Press. Berkeley, California. 259 p.

Cervantes-Badillo, M. G. 2006. Escrutinio de compuestos bioactivos en especies americanas de muérdago. Tesis, Maestría en Biología Molecular. Instituto Potosino de Investigación Científica y Tecnológica, San Luis Potosí, San Luis Potosí. México. 41 p.

Curtis P., J. 1986. Microtecnia vegetal. Trillas, México, D. F. $106 \mathrm{p}$.

Dettke, G. A. y M. A. Milaneze-Gutierre. 2007. Estudo anatômico dos órgãos vegetativos da hemiparasita Phoradendron mucronatum (DC.) Krug \& Urb. (Viscaceae). Revista Brasileira de Biociệncias 5:534-536.

Erdtman, G. 1966. Pollen morphology and plant taxonomy (Angiosperms). Hafner, New York. 553 p. 
Fahn, A., E. Werker y P. Baas. 1986. Wood anatomy and identification of trees and shrubs from Israel and adjacent regions. The Israel Academy of Science and Humanities, Jerusalem. 82 p.

Font Quer, P. 1982. Diccionario de Botánica. Labor, Barcelona. $1244 \mathrm{p}$.

Fuchs, C. 1963. Fucsin staining with $\mathrm{NaOH}$ clearing for lignified elements of whole plants or plant organ. Stain Technology 39:41-144.

García, R., G. 1998. La familia Loranthaceae (injertos) del estado de Aguascalientes, México. Polibotánica 7:1-14.

Geils, B. W. e I. Vázquez C. 2002. Loranthaceae and Viscaceae in North America. In Mistletoes of North American conifers, B. W. Geils, J. C. Tovar y B. Modoy (coords.). Gen.Tech. Rep. RMRS-GTR-98. U. S. Department of Agriculture, Forest Service, Rocky Mountain Research Station, Ogden, Utah. p. $1-5$.

Geils, B. W., D. Wiens y F. G. Hawksworth. 2002. Phoradendron in Mexico and The United States. In Mistletoes of North American conifers, B. W. Geils, J. C. Tovar y B. Modoy (coords.). Gen. Tech. Rep. RMRS-GTR-98. U. S. Department of Agriculture, Forest Service, Rocky Mountain Research Station, Ogden, Utah. p. 19-28.

Holmgren, K. P., N. H. Holmgren y L. C. Barnett. 1990. Index Herbariorum. Part 1. The herbaria of the world, octava edición. New York Botanical Garden, New York. 693 p.

Johansen, D. A. 1940. Plant microtechnique. McGraw-Hill, New York. 523 p.

Johansson, S., R. J. Gullbo, P. Lindholm, B. Ek, E. Thunberg, G. Samuelsson, R. Lansson, L. Bohlin y P. Claeson. 2003. Small, novel proteins from the mistletoe Phoradendron tomentosum exhibit highly selective cytotoxicity to human breast cancer cells. Cell and Molecular Life Sciences 60:165-175.

Kuijt, J. 1967. On the structure and origin of the seedling of Psittacanthus schiedeanus (Loranthaceae). Canadian Journal of Botany 45:1497-1506.

Kuijt, J. 1986b. Viscaceae. Flora de Ecuador 24:13-112.

Kuijt, J. 1986c. Loranthaceae. Flora de Ecuador 24:115-194.

Kuijt, J. 2003. Monograph of Phoradendron (Viscaceae). Systematic Botany Monographs 66:1-643.

Kuijt, J. 2009. Monograph of Psittacanthus (Loranthaceae). Systematic Botany Monographs 86:1-361.

Metcalfe, C. R. y L. Chalk. 1950. Loranthaceae. Anatomy of the dicotyledons, vol. II. Clarendon Press, Oxford. 1498 p.

Oliva, R. H. 1995. Revisión del género Phoradendron (Viscaceae) para el estado de Veracruz. Tesis, Maestría en Ciencias, Colegio de Postgraduados, Montecillo, Estado de México. 121 p.

Pöll, E. 2006. Los muérdagos de Guatemala (Loranthaceae, Viscaceae y Eremolepidaceae): diversidad, distribución e importancia económica. Biodiversidad de Guatemala, vol. I. Universidad del Valle de Guatemala/ [Ed.] Cano, Guatemala.
Radford, A. E., W. C. Dickinson, J. R. Massey y C. R. Bell. 1974. Vascular plant systematics. Harper \& Row, London. 891 p.

Roberts, N. C. 1989. Baja California plant field guide. Natural History Publishing La Jolla, California, 309 p.

Rodríguez-Cruz, M. E., L. Pérez-Ordaz, B. E. Serrato-Barajas, M. A. Juárez-Oropeza, D. Mascher y C. Paredes. 2003. Endothelium-dependent effects of the ethanolic extract of he mistletoe Psittacanthus calyculatus on the vasomotor responses of rat aortic rings. Journal of Ethnopharmacology $86: 213-218$.

Ruzin S. E. 1999. Plant microtechnique and microscopy. Oxford University Press. New York. 322 p.

Sosa, M. M. y S. G. Tressen. 2002. Las plantas parásitas. In Flora del Iberá, M. M. Arbo y S. G. Tressen (eds.). Editorial Eudene. Corrientes, Argentina. p. 167-178.

Sosa, M. M. 2003. Anatomía foliar de Loranthaceae (sensu lato). Comunicaciones Científicas y Tecnológicas 2003. Universidad Nacional del Nordeste. Corrientes. 3 p.

Varela, B. G. y A. A. Gurni. 1995. Anatomía foliar y caulinar comparativa del muérdago criollo y del muérdago europeo. Acta Farmacéutica Bonaerense 14:21-29.

Varela, B. G., T. Fernández, C. Taira, P. Cerda, R. A. Ricco, E. Caldas, E. Alvarez, A. A. Gurni, S. Hajos y M. L. Wagner. 2001. El "muérdago criollo", Ligaria cuneifolia (R. et P.) Tiegh. -Loranthaceae- desde el uso popular hacia el estudio de los efectos farmacológicos. Dominguezia 17:31-50.

Varela, B. G. y A. A. Gurni. 2003. Análisis micrográfico de dos hemiparásitas argentinas usadasen medicina popular y su aplicación en el control de calidad. Acta Farmacéutica Bonaerense 22:45-52.

Varela B. G., T. Fernández, R. A. Ricco, P. Cerdá, S. E. Hajos, A. A. Gurni, A. Álvarez y M. L. Wagner. 2004. Phoradendron liga (Gill.ex H. et A.) Eichl. (Viscaceae) used in folk medicine: anatomical, phytochemical, and immunochemical studies. Journal of Ethnopharmacology 94:109-116.

Varela, B. G., K. A. Borri, M. J. Ganopol y A. A. Gurni. 2008. Aplicación del índice de estomas y de la diafanización foliar en la identificación de especies de muérdagos argentinos pertenecientes a Loranthaceae. Latin American Journal of Pharmacy 27:28-33.

Vázquez, I. y B. W. Geils. 2002. Psittacanthus in Mexico. In Mistletoes of North American Conifers, B. W. Geils, J. C. Tovar y B. Modoy (coords.). Gen. Tech. Rep. RMRS- GTR98.: U. S. Department of Agriculture, Forest Service, Rocky MountainResearch/Station, Ogden, Utah. p. 9-16.

Venturelli, M. 1981. Embriologia de Struthanthus vulgaris (Loranthaceae-Loranthoideae). Kurtziana 14:73-100.

Venturelli, M. 1983. Estudos embriológicos em Loranthaceae: gênero Tripodanthus. Kurtziana 16:71-90.

Venturelli, M. 1984a. Estudos sobre Struthanthus vulgaris Mart., aspectos anatômicos de raiz adventícea, caule e folha. Revista Brasileira de Botânica 7:79-89. 
Venturelli, M. 1984b. Morfologia e anatomia floral de Struthanthus vulgaris Mart. (Loranthaceae). Revista Brasileira de Botânica 7:121-128

Wilson, C. A. y C. L. Calvin. 2003. Development, taxonomic significance and ecological role of the cuticular epitelium in the Santalales. IAWA Journal 24:129-138.

York, H. H. 1909. The anatomy and some of the biological aspects of the "American mistletoe" Phoradendron flavescens (Pursh) Nutt. Texas University Bulletin 120, Sciences series 13:1-58. 